\section{SEISMOLOGY IN BRITAIN}

A

VERY wide range of activity in the fields of pure and applied seismology by British seismologists is referred, 0 in the recently published fiftythird report the Committee on Seismological Investigatign of the British Association for the Advancentey of Science.

The rork of the International Seismological Sumrary is carried out by a staff of three, headed br Mr. J. S. Hughes. Through the courtesy of the dilector of the Meteorological Office it is housed in two huts at Kew Observatory. The bound volumes for 1936 have been issued, as also have more recent quarterly parts. Manuscript for 1937 is compiled. The past year has seen the change-over from the use of normal geographic co-ordinates for the positions of observing stations as a basis for the estimate of travel times to that of geocentric direction-cosines. Such a change means that no distances, calculated for epicentres used before 1937, can be used for preliminary epicentres. The slowing up of the work, now that the system is well in hand, is thought, however, to be inappreciable. Prof. H. Jeffreys (director) and Mr. J. S. Hughes now wish to know what readings they may expect to receive from observatories for the period after the outbreak of hostilities in 1939.

There have been few British earthquakes recently. The earthquake of May 28, 1948, at 17h. $02 \frac{1}{2} \mathrm{~m}$., G.M.T., was felt over a considerable region of Norfolk, Suffolk and Cambridgeshire, but was accompanied by no appreciable damage. It was recorded by the Kew seismographs, both short-period and Galitzin, $P g$ occurring at $17 \mathrm{~h} .02 \mathrm{~m}$. 53s. G.M.T. and $S g 14$ sec. later; the distance from Kew was therefore about $120 \mathrm{~km}$. Dr. A. T. Dollar, of the University of Glasgow, has resumed the collection of macroseismic data concerning British earthquakes, and it is hoped
The seismological work of the Department of Geodesy and Geophysies at the University of Cam. bridge has included Prof. E. R. Lapwood's theoretical investigation of the diffraction effects at the surface of a semi-infinite homogeneous elastic medium after a pulse has been emitted by a buried line source. Prof. Lapwood has shown that at distances large compared with the depth of the source, the disturbance at the time of arrival of the direct $S$-pulse differs from that at the time of arrival of the $P$-pulse in being smudged or blunted. Some seismic work at sea has been done; microseisms with frequencies greater than 8 cycles per sec. have been investigated and are thought to be man-made; and short-range explosion seismology has been done in the Lake District and in Wales. Mr. P. L. Willmore has designed a moving-coil seismograph with a nearly constant response to ground velocities of frequency 2-25 cycles per sec., and a maximum sensitivity of $5,000 \mathrm{~cm}$. per cm. per sec. Mr. M. N. Hill has designed a long-period inductance-bridge seismograph. Mr. Willmore spent several months in Germany, arranging for seismological observations to be made on the tremors from the explosion on Heligoland of nearly 4,000 tons of ammunition on April 18, 1947. Observations were made by portable seismographs in Germany, chiefly from the Geophysical Institutes at Göttingen and Celle, in Holland and in Denmark, and by two ships in the North Sea. The tremors were also recorded by observatory seismographs in Belgium, France, England, Czechoslovakia and Switzerland. Travel times were observed at distances of 50-1,000 km. from Heligoland; these were supplemented by the observations up to $50 \mathrm{~km}$. of the explosion of about 400 tons of explosive near Soltau in the autumn of 1946. The characteristics of the artificial earthquake wave phases are given in the table, which also includes figures for the thicknesses of the assumed layers.

\begin{tabular}{|c|c|c|c|c|}
\hline Phase & Velocity & Starting time & Thickness & Standard deviation of one observation \\
\hline $\begin{array}{l}\text { Sedimentary } P \text { wave } \\
P g \text { (NGar stations) } \\
P g \text { (Distant stations) }\end{array}$ & $\begin{array}{l}1 \cdot 6-5 \cdot 4 \mathrm{~km} . / \mathrm{sec} . \\
6 \cdot 06 \pm 0 \cdot 09 \\
4 \cdot 9=5 \cdot 5\end{array}$ & $2 \cdot 8 \stackrel{0}{ \pm 0} \cdot \mathbf{2}$ & $\begin{aligned} 9 \cdot 01 & \pm 1 \mathrm{~km} \\
17 \cdot 4 & \pm 2 \mathrm{~km} .\end{aligned}$ & $\begin{array}{l}0.16 \text { sec. on regional means } \\
3 \text { sec. for } 1 \text { layer. } 0.50 \text { and } 0.86\end{array}$ \\
\hline$\underset{R}{P n}$ & $\begin{array}{l}8 \cdot 18 \pm 0 \cdot 014 \\
4 \cdot 36 \pm 0 \cdot 06 \\
3 \cdot 35 \pm 0 \cdot 1\end{array}$ & $\begin{array}{l}7 \cdot 37 \pm 0 \cdot 1 \\
2 \cdot 8 \text { 圭 } 1 \cdot 3 \\
4 \cdot 6\end{array}$ & 二 & 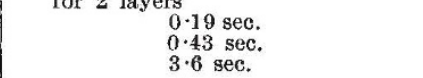 \\
\hline
\end{tabular}

to publish his collected observations on the small earthquakes of April 2, 1948, at Bethesda, Carnarvonshire, and May 31, 1948, at Ullapool, Ross-shire, together with later observations in 1949.

Two of the Committee's seismographs were removed from the University Observatory, Oxford, to Down House, Downe, Kent, in 1937, and were put in the care of Dr. O. J. R. Howarth. They were assembled by Miss E. F. Bellamy and later calibrated by Mr. J. S. Hughes and Mr. E. N. Lawrence. Dr. Howarth has since been comparing the seismograms which he has obtained with the readings from the seismograms obtained at the observatories at Kew and Durham, and also with the preliminary epicentres on the cards issued by the United States Coast and Geodetic Survey; he has also sent observations on microseisms to Dr. G. E. R. Deacon at the Admiralty Research Laboratory. In addition, the Committeo has Milne-Shaw seismographs at Edinburgh (recording suspended), Cape Town, Perth (Western Australia) and Suva (Fiji), and a Jagger shock recorder at Comrie, Perthshire.
$R$ appears to be a wave, according to Willmore, which was propagated through the ultrabasic layer, after suffering reflexion from the surface at one point in its path. Prof. C. Charlier is of the opinion that this observed phase was propagated through a separate layer in the earth. Calculations from the measurement of seismograms give a value of $10^{17} \mathrm{ergs}$ for the energy transformed into earthquake waves by the whole explosion. Measurements of the crater show that $1.5 \times 10^{18}$ ergs were expended in moving the rock above the charge, while the total thermal energy of the explosive was $1.3 \times 10^{20}$ ergs.

Dr. G. E. R. Deacon reports that work at the Admiralty Research Laboratory seems to throw some light on the origin of microseisms. It has been shown that pressure fluctuations due to sea-waves likely to be responsible for microseisms occur when there is interference between sea-wave groups of the same frequency travelling in opposite directions. This interference may arise in the neighbourhood of a fast-moving depression over the sea, or in a coastal region where energy is being reflected from the 
shore. The theory suggests a definit 9 two to one relationship between the periods of the sea-waves and microseisms, which has been confirmed by observations. Further, by submitting simultaneous records of waves and microseisms to frequency analysis, it has been thought safe to conclude that a depression moving rapidly over deep water north of the Azores caused microseisms at Kew. Microseisms on Kew seismograms can be detected some thirty hours before the swell from a distant storm reaches the coast.

ERnest Tillotson

$$
\text { ph }
$$

\section{MAGNETIC AMPLIFIERS}

$\mathrm{T}$ HE thermionic valve amplifier is so universal in its applicat nn al even the existence of other means of amplfying ends to be overlooked. Two papers read receftly before the Institution of Electrical Engineers record developments in magnetic amblip rs, and indicate the field of application within which such amplifiers possess advantages. Thespe porsers, "Magnetic Amplifiers", by A. G. Mibles, as "A Theoretical and Experimental Study of the Series-Connected Magnetic Amplifier", by H. M. Gale and P. D. Atkinson, were presented on December 2, 1948.

Essentially the principle of the magnetic amplifier is that of controlling the current in an A.c. circuit by varying, by means of an auxiliary D.C. circuit, the impedance of an iron-cored reactor in series with the load. The D.c. circuit thus effects its control by producing magnetic saturation of the reactor core. This principle has been known and has been applied for many years, indeed since the period of the First World War; but it was not until high-permeability nickel-iron alloys and metal rectifiers became available that rapid development of the magnetic amplifier for a wide range of applications took place.

The basic circuit arrangements of magnetic amplifiers have now assumed fairly well established forms, and the present papers give a systematic theoretical treatment and design procedure for the standard circuits. As a rule the magnetic amplifier operates as a D.C. amplifier in the sense that the input or controlling current is a small direct current, and the output is again a direct current produced by the rectification of the alternating current passed by two reactors, the reactance of which is controlled by the input. A simple, single-stage magnetic amplifier employing high-permeability cores might give a power-gain of the order of 10 to 20. This gain may be very greatly increased, however, by the use of positive feed-back. Feed-back is applied by circulating the direct output current through an additional winding on the cores. If the magnetic effect of this feed-back winding is in such a direction as to reinforce that of the input current, there is partial self-excitation which increases the ratio of output current to input current. The effects of feed-back are closely analogous to those obtained with thermionic amplifiers, and excessive positive feed-back will give rise to instability. Positive feed-back is commonly utilized to obtain power gains per stage of the order of 2,000 . Without feed-back a magnetic amplifier does not discriminate between positive and negative input signals; but with the application of feed-back, reversal of the polarizing flux changes the feed-back from positive to negative, and discrimination results. Magnetic amplifiers commonly operate with input powers of the order of a microwatt, and it is stated in one of the papers that $10^{-8}$ watt may be regarded as the lower usable limit of input power.

Perhaps the most significant difference between the behaviour of the magnetic amplifier and that of the thermionic amplifier lies in the time delay of the response of the magnetic amplifier to a sudden change of input. The build-up of the steady state following a sudden alteration of input is approximately exponential, and the response-time of magnetic amplifiers is usually expressed as the time-constant of an approximately equivalent exponential rise. This time delay, which is practically inversely proportional to the frequency of the A.c. supply and increases in proportion to the stage amplification, is one of the important limiting factors in the application of magnetic amplifiers. In order to obtain a high ratio of amplification to time-constant it is desirable to connect a number of stages in cascade, since the overall amplification is the product of the amplifications of the individual stages, whereas the total time-constant is, very roughly, the sum of the time-constants of the stages.

It is interesting to note that in the two papers the theoretical analysis proceeds along quite different lines, and different approximate-design techniques are developed. It is pointed out that a magnetic amplifier to control a given power output is ordinarily considerably larger than the corresponding power transformer, and supply frequencies in the range 400-1,600 c. s. are commonly employed in order to reduce the size of the equipment. The equivalent exponential delay of an amplifier is stated to correspond to a time-constant of the order of 2-100 cycles of the supply frequency. JAMES GREIG

\section{$I_{\mathrm{d}}^{\mathrm{N}}$}

\section{RECRUITMENT AND TRAINING FOR THE IRON AND STEEL} INDUSTRY order that continuous and rapid technical developmans in the iron and steel industry shall not outruiline capabilities of the men who will be required.to operate the processes involved, the Brish Iron and Steel Federation has recently pre atred recruitment and training schemes to benefit the industry as a whole. Based on the experience gained by various firms who have already developed training programmes of a far-reaching character, the Recruitment and Training Committee of the Federation has introduced a sample training scheme which has been circulated to all member firms. In order that the scheme should be fully discussed and improved, a Conference was held at Ashorne Hill, Leamington, on January 14-16, 1949, under the chairmanship of Mr. Gerald Steel, joint managing director of the United Steel Companies. The Conference was attended by representatives of member firms from all parts of Britain, and included production managers as well as personnel officers of various grades.

Pointing out that the number of youths in industry between the ages of 14-18 years had fallen from $3 \frac{1}{4}$ millions in 1938 to $2 \frac{1}{2}$ millions in 1947 , Mr. A. Goodram, of Samuel Fox and Co., Ltd., discussed the training of the junior operative both from the economic and social points of view. In his own Company the 